\title{
Energy security of northern and arctic isolated territories
}

\author{
Violetta Kiushkina ${ }^{1, *}$, and Boris Lukutin ${ }^{2}$ \\ ${ }^{1}$ FSAEE HE Technical Institute (branch) of the North East Federal University. Nerungri, Russia \\ ${ }^{2}$ National Research Tomsk Polytechnic University, Tomsk Energy Engineering School, Tomsk, Russia
}

\begin{abstract}
The given investigation considers the peculiarities of decentralized power supply, taking into account specific features of North and Arctic Territories. Aautonomous systems of power supply (ASPS) operate in the regions of the Far North under the most difficult circumstances. This set of territorial factors reflecting the peculiar features of geographical location and situational factors group of autonomous power. Multi-factor approach and complexity of the power problems in modern decentralized energy puts forward ES as the most important component of regions national security. The degree of large differences between Northern and power isolated regions from other territories confirms the need for methodological approaches to the diagnosis. A priori some indicators have their value and the inherited threatening group can complicate in terms of infrastructural isolation and severity of the climate for the functioning of power generation and functioning within quite different types of consumers. Structuralization of the maximum peculiar threats of different nature and the main consequences for ES investigated parts allows formulating a common definition for the exclusively decentralized zones of severe climate conditions territories. Due to the context of autonomy the clear boundaries of concepts of threshold ES states of the researched systems are appropriate: secure, depressive, emergency.
\end{abstract}

\section{Introduction}

Energy development regions have the following negative trends [1] - resource quality is deteriorating as the effectiveness of geological prospecting is low, difficulties to extract resources; excessive wear of FCS at low updating rate with residual technical resource of the large part of equipment, emergencies in fuel and energy systems, lack of serious improvements in energy saving, etc.

Through the analysis of energy security (ES) of existing research scientific papers a sufficiently distinctive list of threats to energy and energy enterprises is formulated. One can claim that threats on the Northern areas arise as a result of natural processes and

\footnotetext{
*Corresponding author: viola75@mail.ru
} 
unfocused and non-addressed acts or omissions in all branches of economy resulting in bad consequences the origin of which may be an unfavorable and poor development of economic and social processes, existing conditions of territories in internal and external energy enterprise area. Consideration of such threats while assessing the Northern decentralized areas requires some analysis and detection of significantly emerging negative and potentially dangerous phenomena among the inherent threats with defining specificity of the investigated territories.

In the decentralized power zones of the Northern and Arctic Territories the risks always occur because of registered factors and conditions of their existence and functioning. In this case we can say that the risks even in the system of favorable indicator values though insignificant will take place as investigated energy areas with existing specific features are not able to "resist" the impacts of natural or territorial threats which a priori influence them. Assume this condition as partially safe for decentralized zones, because it is inevitable to find them in the current circumstances.

Regions related to the North differ greatly in life support and management conditions. For these reasons the area is deeply heterogeneous in economic and social development. The main common features of the economy and life in the North are: unfavourable climate (with fluctuations from absolute to moderate discomfort), permafrost expansion, a large distance from major economic and cultural centres, high transportation expenses, increase in the cost of manufacturing and construction, the high cost of living, etc. These negative factors (fig.1) are essential enough and in each of the main types of the problem regions the zones are singled out according to the character of a complex influence of environment on the living conditions and production.

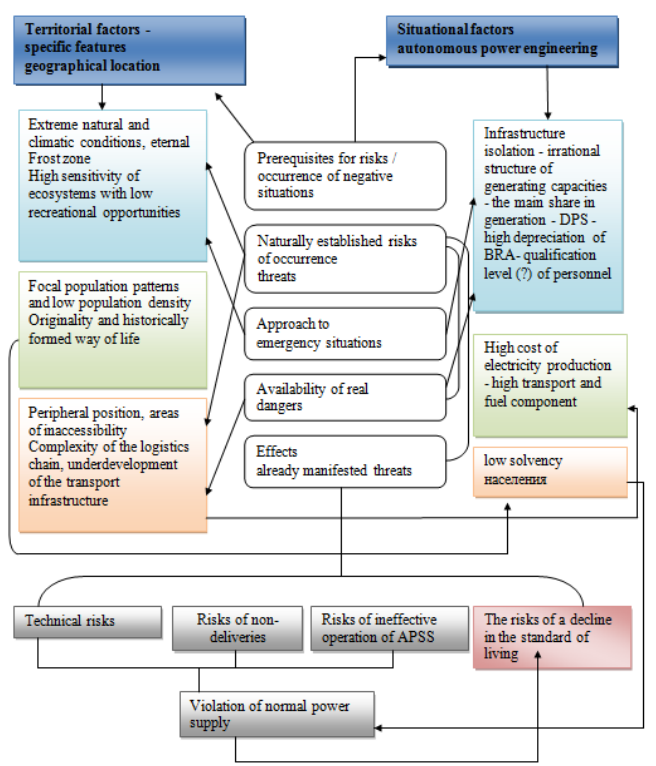

Fig. 1. Local backgrounds for emergency occurrence to the ES of decentralized power areas of the Northern and Arctic zones

The combination of territorial factors (specific geographic decentralized northern areas) and situational factors of autonomous energy makes up the structural basis for the model of the local emergency measures i.e. the risk reduction of the safety level of ES on the investigated territories. It is vividly observed on the developed scheme (fig.1). Every emergency sign or a combination of different risk levels concerning the ES threats, 
vulnerability of successful status of decentralized power area requires the individual consideration by the evaluation indicators taking into account the territory specificities.

\section{Specificity of peculiarity assessment of decentralized Northern energy areas}

One can single out several main positions in the peculiarity structure of decentralized power supply.

\subsection{Power consumer of the decentralized power supply territory}

One more factor distinguishing North zone from the rest is the peculiarity of resettlement and population density (fig. 2). This factor is historically influenced by natural and socio-economic factors and characterized the areas by the predominant types of settlements, the degree of economic development.

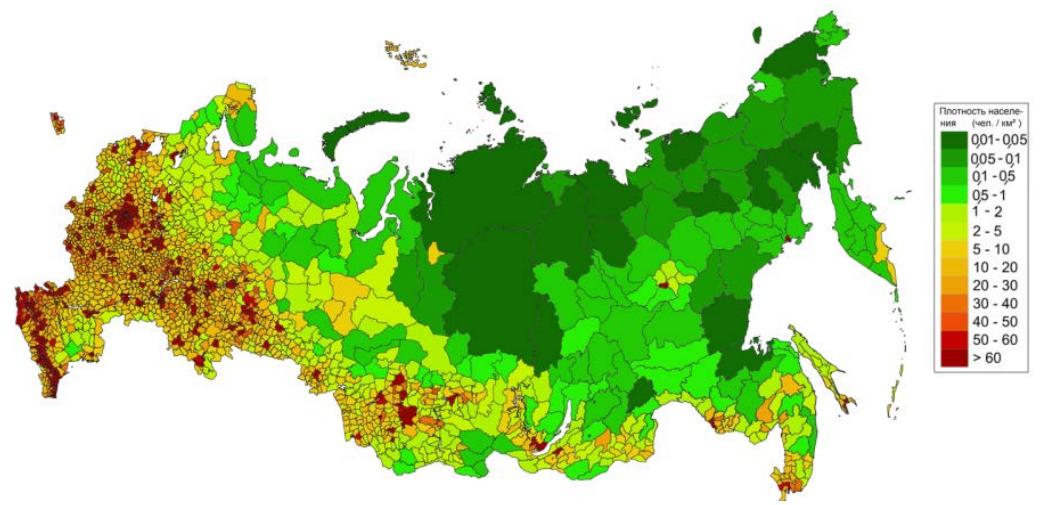

Fig. 2. Population density of Russian Federation territory [3]

The predominance of dispersed and specific in energy supply enterprises which are considered as isolated small northern consumers (mining, processing, logging and fish processing plants, farms, folk handicrafts villages, small rural settlements) of localized properties with significant distances from each other and the concentration of processing industries and service sectors in a limited number of large and medium-sized towns in the form of enclaves requires special approach at the regional level to ensure ES of isolated territories and clarification of its indicative values while using in assessing of decentralized territories.

The Northern part of the Far East is inhabited by people involved in fishing, horse and reindeer breeding, commercial hunting, agriculture, arts and crafts, folk crafts, constructing national traditional dwellings and other buildings which are necessary for common kind of economic activities. In rural territories of other regions indigenous population prevails too (fig. 3) having fishing and agricultural activities. The small indigenous peoples of the North (SIPN) are peoples of less than 50 thousand people. The traditional economic activity of native minorities of the North covers developed area with roaming routes of reindeer farmers, seasonal hunting routs, gatherers, fishermen, sacred recreation areas, etc. which provides the traditional way of life [2]. The situation of the small indigenous peoples of the North is complicated by difficulties to link their traditional lifestyles to modern economic conditions. The low level of competitiveness of traditional economic activities is due to the small production volumes, high transport costs, absence of modern enterprises and technologies for complex processing of raw materials and biological resources. The crisis of traditional economic activities results in exacerbation of social problems. Standard of 
living of a considerable part of citizens of small indigenous peoples of the North living in rural areas or roaming is below the average quality life level in Russia. Intensive industrial exploitation of natural resources in the northern territories of the Russian Federation significantly reduced the ability to have traditional economic activity of the small indigenous peoples of the North and violated their traditional way of life.

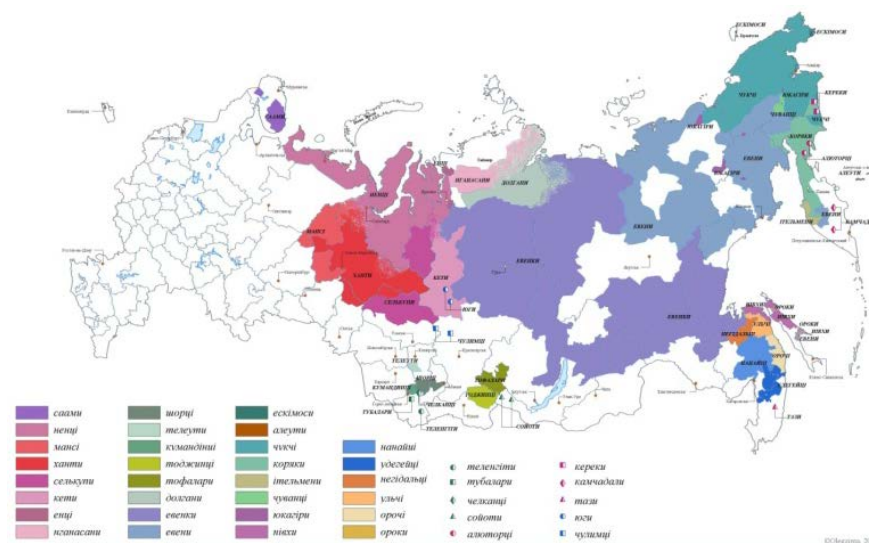

Fig. 3. Modern habitat of small indigenous peoples of the North, Siberia and Far East of Russian Federation [2]

Users of fishing and mining branches of industries are characterized by relatively stable load schedule, while objects of livestock and population are characterized by extremely unstable load schedules.

In the objects group of cattle breeding predominate farms, which are in the spring, summer, autumn or winter pastures depending on the time of year. Among the dispersed agricultural production groups the most intensive energy consumers are the small settlements. In some regions of decentralized territories load peaks occur in autumn or summer not in winter as in the most regions. Local peculiarities can significantly influence the choice of power supply scheme and require detailed and local study. Thus, the interconnection of the population factor, the economy sectors, the length of daylight hours, air temperature have a direct impact on energy efficiency of autonomous power systems in the northern territories.

\subsection{Autonomous systems of power supply of the Northern territories}

The major share (96\%) in the generation of electrical energy in autonomous power supply systems of (APSS) falls on the most wide spread energy sources for the territories with decentralized power supply: electricity-diesel power plants, typical schemes of which have not been changed for many years, though they have a number of disadvantages. In the Far North and remote regions of Siberia and Far East the small power objects are the basis of the energy supply. Over 6 thousand of DES (diesel electricity stations) operate on the territory of the North, the total installed capacity is more than $3000 \mathrm{Mw}$, and they produce about 6 billion of kWh of electricity per year.

In decentralized energy supply sector of the Far Eastern Federal Region diesel generation is dominated: about 500 units with the capacity of $670 \mathrm{MW}$; annual fuel diesel consumption is 254 thousand tons of equivalent fuel. Low technical and economic indicators are reflected in the specific fuel consumption which makes up 500-600 grams of equivalent fuel $/ \mathrm{kWh}$. Isolated power supply systems have personnel and supervisors of low or no qualifications. As a consequence there is an increasing violation of stable operation of power stations, inefficient use of energy resources, and reduction of productivity of the 
local energy object. The result is the untimely or incomplete taking measures to ensure ES, lack of optimality and poor implementation.

In decentralized areas of the northern regions due to the low reliability of production systems and equipment technogenic threats take place. Power plant equipment on such areas is characterized by a diversity of used units of DES which complicates their service processes, repairs and reduces the exploitation reliability. The values of the indicator of wear out of the main production assets (MPA) of the region fuel and energy complex demonstrates that in recent years the situation with worn-out state of power production asserts has worsened. As electricity sources hundreds of worn out service life or with critically discounted rates power units of diesel-electric stations with very low efficiency are used. The buildings and structures during for the period of operation of DES have undergone irreversible changes. Some power generators are in the condition of inundation during spring floods and require transition to a new location. Auxiliary equipment (pumps, compressors, electro and recycling boilers, cooling towers, closure ties, piping, fuel-oil production, water production, ventilation etc.) needs to be substituted. Long term lag in inputting electric power results in reduction of energy reliability.

In the area of decentralized power supply large production capacity units do not operate, so we can assume that the power supply is social by nature. And it is a remote decentralized energy sociality, hard-to-reach, underpopulated Northern Territories and Arctic zones do not have the ability to generally accepted expectations of return efficiency investments. Other aspects should work to strengthen ES.

The industrial, economic, technological, raw threats manifest explicitly. None of this provides ecological and emergency power sources safety and moves to a risky situation in terms of reliability of power supply consumers.

\subsection{Fuel resources supply}

From the point of view of ES of the northern regions the presence or absence of deposits of energy resources, the degree of deposits exploration, security of supply of energy resources to the DES and boilers, the development of renewable energy in the region, the need for energy consumers in the region, etc. can be affecting factors. A generalized factor of ES supplement implies diversification of energy resources supply routes into the region, and search for possible diversification of own energy sources (for example, alternative energy). The territories are located in the most disadvantageous position and the reliability of energy supply greatly depends on the seasonal supply of imported diesel fuel. Decentralized territories do not have availability of diesel fuel, which is the only resource for the advantageous share of sources of power zones. In the logistic chain of territories under consideration there is the Northern sea route, which runs along the northern coasts of Russia on the seas of the Arctic Ocean, connecting into a single transport system European and far eastern ports of Russia, as well as the mouths of the Siberian rivers shipping routes. Duration of navigation is 2-4 months, the use of icebreakers enables one to use the route all the year round. The main drawback of the Northern sea route is the severe natural conditions restricting navigation time. Within the frames of the "Northern delivery" 6-8 million tons of petrol, oil and lubricants and up to 20-25 million tons of coal are imported in the autonomous power supply regions of the far North, Siberia and the Far East annually. Logistic structure and scheme of fuel delivery is processed and not simplified by its complexity, as for acceptability in terms of ES it has very high risks. So it is necessary to monitor the facts that lead to threats manifestation of risks and a priori exist on these territories. Scheme of logistics indicator implementation has a discrete (deponent) participants and repeated continuous participants with long downtime on the proveded or spontaneously arranged situations having a threatening impact in ensuring ES. 


\section{The concept of energy security of northern decentralized areas}

If consider the interpretation of energy security of the decentralized areas in general, one can assume it as a power supply model involving a long-term outlook for supplying electricity, fuel and necessary resources for functioning of autonomous power supply systems on the basis of different research works.

In conceptual claims of Russia's Energy Security Doctrine approved in 2012 by RF President's decree, regional energy security is an integrated feature of energy consumers status on the territory of the constituent unit or Federal District of the Russian Federation defined by the fuel and energy balance of the region (at the expense of its own power supply including the potential of energy savings and guaranteed external energy supplies) and self-sufficiency in energy emergency supply situations. A local (private) energy security is defined as the status of a reliable energy supply and the functioning of vitally important activities of a single object (military, Government, social) and subject (person), and the absence of threats to other subjects and objects by its activity.

Thus, taking into account the definitions and threats schemes model it is possible to form a generalized definition of ES exclusively for decentralized areas of the Northern territories and Far North: it is a confident protection status of power areas from inherent threats arising from infrastructural territory isolation of the local supply object ensuring diversification of complex fuel and energy and favourable conditions for the operation and local energy objects self-sufficiency in maintaining sustainability of ecological system immunity, meeting demands of power quality taking into account harsh long term climatic conditions, preventing threatening situation to any working systems and subsystems of power energy enterprises.

Taking into consideration the specificity of decentralized northern regions areas consumers and the concept of development [4] of the majority of such consumers, the sustainable development zones mans the stable development of small isolated settlements, ensuring the fulfillment the economic functions: agricultural production and services, public goods; retention of agriculture and fishing lifestyle, cultural identity, preservation of historically cultivated landscapes; increase of population life quality level, the maintenance of ecological safety.

Therefore, the definition of the conceptual scientific terms interprets the energy security of the investigated territories.

ES object of decentralized power areas is infrastructurally isolated, self-contained power or heat supply systems.

The subject of the decentralized power areas is an operational monitoring process of development and functioning indicators status and the functioning and timely positions modeling in the socio-economic impact and environmental reference point through the specified response forms to indicators state changes to the worse, the negative situations background, natural risks of threats occurrence, emergency approach situations, existence of real dangers and resulting emergency effects, protection, prevention and rehabilitation.

The purpose of decentralized power areas ES studying is providing of local power object self-sufficiency with protection of vitally important functions and interconnected related systems (fuel-supply chain, environment and economic security, availability of electric energy, natural-resource-orientation, operational reliability) under conditions of situational isolation factors and abnormal climate severeness.

The essence of ES as an energy category involves energy well-being protection of the decentralized power areas, sustainable preservation of vital activity of isolated Northern Territories and Arctic zones, indigenous culture, comfortable residence settlements through the provision of all components and derivatives of complex energy enterprises processes. 


\section{Energy security status monitoring of the northern power areas}

\subsection{Informational system}

The ability to monitor the energy security status of the decentralized power area is due to the developed algorithm. The scheme structure contains several modules:

a. Basic module includes territories data information, generating installations, technical characteristics and other data.

Data are based on calculation procedures and visual presentation of statistical information sets: graphic data display (age equipment composition and population histogram, etc.); original data for the indicators calculation; the speed of reaction to an accident-technical risks; the cost of electricity, fuel unit costs, investment, number/types/power of ASES, etc.

b. Environmental zone module is ecological component ES regionalizing in mapsschemes with the thematic layers (overlaying all influencing factors) and area highlighting the most dangerous situations threatening and violating environmental territory "immunity".

c. MODULE 1. Potential renewable sources of energy (RSE) features

d. MODULE 2. ES status levels:

d.1. Calculated module (Analytical Unit, Fig. 4) enables to input the current data for the calculation of indicative figures and monitor capability. Sufficient statistical information makes possible to observe the fractures in the situation: the presence of negative factors and interrelation of high risks of threats occurrence demonstrates the rate of indicator status worsening.

d.2. A comparative result calculation module with threshold values defines ES level.

This procedure moves to render map visualization of ES levels; to threshold attribution the level index of ES (0-1); to graphic representation of $\mathrm{H}$ - distribution of the level ES.

f. Module 2 consequences

$f .1$. The requirement to input data system for optimizing ASES is absence of access to transition to another level without emergency optimization. It is preceded by a classification of importance level sequence on indicative clusters:

-1 line 1 importance level (emergency ES level). Where emergency situation is signaled on reliability blocks, ASES structure, etc.: the recommendation for transition to choose ASES structure by reference;

-2 line (depressive ES level: there is a symptom of decreasing the security level;

-3 line (ES safety level): recommendation of structure choices of ASES with RES to save fuel resources. Each line has its own variant to choose the effective way to improve ES, which can be accessed

f.2. Supplementary modules:

- reference (request) to the NASA database on RES

- reference (request) for selecting ASES programme

- reference (request) to the programme of definition the ES level thresholds 


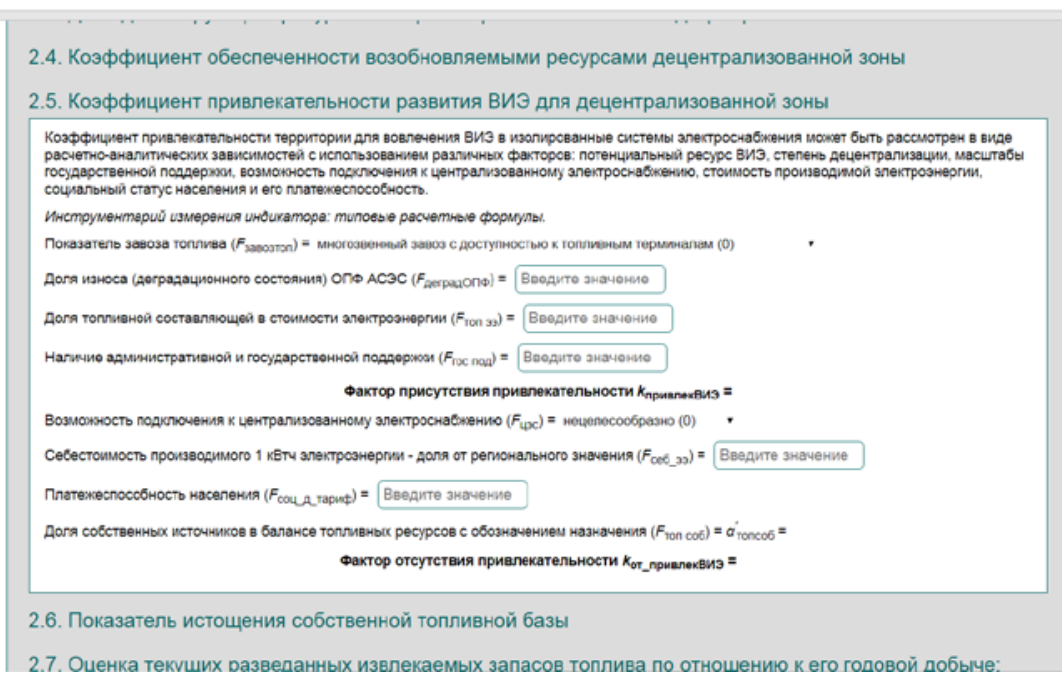

Fig. 4. The example of the window of the information integrated system of the calculated analytical system block

Data sets representing tables, various regulations, technical and technological documentation, various types of maps, positioning of power objects in time and space of Sakha (Yakutia) and their characteristics, power objects conditions, data coming directly from the automatic process control system (APCS), territorial clusters, etc. is transmitted into the basic module.

The basic module is the data storage, or in other words a central server of receiving, classification and data storage. Then received information that requires further processing and analysis transmits into the analytical module or follow module.

The follow module is a support system module including external links (on various issues, external databases, prompts to the modeling of hybrid of autonomous complexes operation modes involving RES) and internal references (requests to various databases and modules). Where a part of the data is transmitted directly into the integration module into the layers of the IMS (information measuring system), the other part is in the systemsoftware solutions block.

Processed, sorted out information is transmitted into the system-software solutions module for technical and/or technological tasks. It is responsible for recommendations for enhancing energy security level; recommendations for local installation of power objects; forecasting indicators of reliability and ES (from static information); selecting proposals program of automated energy supply system.

In the long run, the basic information is presented in a block of data visualization. This information is displayed on the user and administrative interfaces.

Development of the analytical module comprising the integrated information system operational ES monitoring provides rate to identify problems and determine the direction of the solution.

\subsection{System response on ES level signal}

On the proposed scheme basis is made a response system algorithm on the level of ES status of decentralized power area. 
Based on visualization of vulnerable and weak positions and analytical processing of operational information a possibility to raise the quality of strategic decisions is vividly seen. A joint diagram (fig. 5) reflects the total system performance according to the following algorithm: condition-level visualization based on the result of indicator assessment gives the user the possibility to transmit a set of activities, provided that the condition has the emergency status; when a user works with the field of the best conditions the system gives recommendations of a general nature and let the transition move.

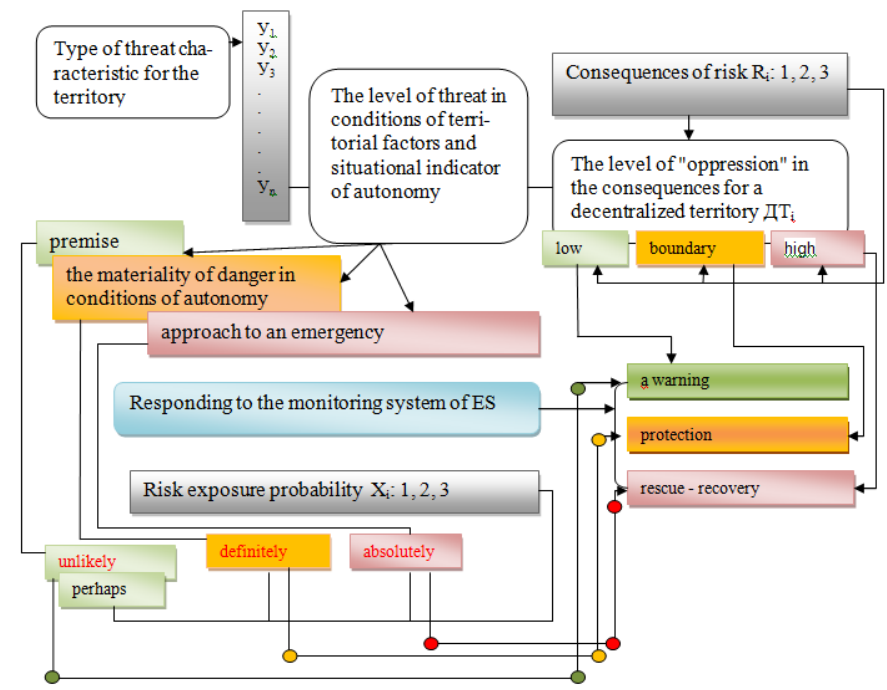

Fig.5. The scheme of interconnection between the probable risk influence and area "depression" level from the point of view of ES threats

The strategy of the systems performance is based on the idea of priority of obtaining and implementing of issue solutions in ensuring ES of those objects or areas where the condition level is so crucial and ensuring of minimum living conditions and functioning are under the threat. The most important event is in the priority rank indicators and the value of the extraordinary level results in high risks and threats for enterprises and people.

The combination of the degree of threats susceptibility and occurrence of a certain vulnerability level which is denoted is denoted as "depression". "The depressed" decentralized status of the power area in terms of ES are assumed indicators and abilities decline that characterize the providing comfortable life conditions of the population and the functioning of the energy enterprises with a particular degree of vulnerability of ES protection level associated with negative events (the intensity of the risk, severity of consequences). To visualize the priority threats scheme defining threats relevance indicators due to the high likelihood of emergency situations, damages, catastrophic events a chain is formed, represented on fig. 5 .

\section{Implications}

The analysis of the current situation in the Russian Federation energy structure (the lack of sufficient investment for updating the capital equipment, significant instability in the energy supply of various category consumers) and world trends of energy development and its subsystems confirms the advantage of small decentralized power enterprises as an optimal basis for the introduction of new technologies and investment attractiveness and 
one of the ways out of the crisis on a particular territory. Observation of negative factors along with the areas historical circumstances threatens many aspects to create a comfortable environment for living and power facilities functioning. Decentralized power needs reliability as a key factor.

Definition analysis demonstrates their common ES semantic direction and diverse coverage of various objects, factors, causal connection, figures, indicators, technical specifications, statistics, etc. This is confirmed by the existing investigations and the need to take into account the uniqueness and specificity of each area unit cluster, local node, region, etc. The research work gives a definition of ES exclusively for decentralized areas with severe climatic conditions on the basis of the maximum intrinsic threats of different origin and denoting the main implications of ES threats.

The combination of the selected modules in the developed monitoring status of ES in the remote and isolated territories of decentralized power zones system reveals the systematic level monitoring. The main module in the system is assessment and analytical unit which is based on the introduction of modern current data to determine the position of the indicator values. Threshold values while assessing decentralized ES power zones are tough enough, because of the existed autonomous power enterprises under operating conditions.

\section{Acknowledgements}

The study was carried out with the financial support of the Russian Foundation for Basic Research and the Subject of the Russian Federation - the Republic of Sakha (Yakutia) № 18-48-140010

\section{References}

1. V.V. Bushuev, N.I. Voropay, S.M. Senderov, V.V. Sayenko. About energy security doctrine of Russia//Regional Economy. 2, pp. $42-43$ (2012).

2. Internet resource. Free encyclopedia materials: indigenous and minority peoples of the North and the Far East. URL: https://ru.wikipedia.org/wiki (Accenssed 17.03.2018)

3. Internet resource. Free encyclopedia materials: resettlement of the population of the Russian Federation. URL: http://ru.wikipedia.org/ (Accenssed 17.03.2018)

4. On the concept of sustainable development in rural areas of the Russian Federation the period up to 2020 year [electronic resource]: a digest of parliamentary hearings. April 23, 2009 year. URL: http://council.gov.ru/failes/journalsf/number/20100218143733.pdf (Accenssed 11.10.2010) 